\title{
Unbound pavement materials' response to varying groundwater table analysed by falling weight deflectometer
}

\author{
M. Fladvad \\ Road Technology, Norwegian Public Roads Administration, Trondheim, Norway \\ Department of Geoscience and Petroleum, NTNU - Norwegian University of Science and Technology, \\ Trondheim, Norway \\ S. Erlingsson \\ Pavement Technology, Swedish National Road and Transport Research Institute (VTI),Linköping, Sweden \\ Faculty of Civil and Environmental Engineering, University of Iceland, Reykjavik, Iceland
}

\begin{abstract}
Expected climate changes will in many areas represent a shift towards increased precipitation and more intense rainfall events. This may lead to increased moisture within road structures and possible overloading of road drainage systems. Pavement design methods must therefore be able to predict the behaviour of pavement materials at increased moisture levels. An instrumented accelerated pavement test (APT) has been conducted on two thin flexible pavement structures with coarse-grained unbound base course and subbase materials using a heavy vehicle simulator (HVS). The two pavement structures were identical except for the particle size distribution (PSD) of the subbase materials, where one had a dense $0 / 90 \mathrm{~mm}$ curve with a controlled fines content, and the other had an open-graded 22/90 $\mathrm{mm}$ curve. The APT was conducted using constant dual wheel loading, and three different groundwater levels were induced in order to change the moisture content in the structures. Falling weight deflectometer (FWD) measurements were conducted at each groundwater level during the APT. Additional FWD measurements were conducted as the groundwater was lowered after the APT loading was finished. The moisture content in the unbound materials was continuously measured throughout the test. The analysis is focussed on the response of the unbound aggregate layers to varying moisture levels in the pavement structures. Analysis results show how the dense- and open-graded materials respond to the moving groundwater table, and how this affects the deflection of the full structures.
\end{abstract}

Keywords: Falling weight deflectometer, groundwater table, unbound granular materials, large-size aggregates, accelerated pavement testing

\section{INTRODUCTION}

Climate changes are expected to result in increased precipitation and more intense rainfall events in many regions (Seneviratne et al., 2012). Such changes in environmental conditions may lead to increased moisture in unbound pavement materials. Overloading of road drainage systems is another potential effect, which may lead to saturation of pavement materials.

Pavement saturation during flooding is one of the key deterioration processes that result in degradation of pavement materials ( $\mathrm{Lu}$ et al., 2018). When unbound materials are saturated, pavement structures observe a significant loss of structural capacity (Elshaer et al., 2019). As 
the moisture content increases, the friction between aggregate particles becomes lower, and the resistance to differential particle deformation is reduced, leading to a reduced resilient modulus of unbound aggregates (Lekarp and Dawson, 1998; ARA Inc., 2004; Erlingsson, 2010).

The moisture content in pavement materials is affected by both groundwater level, drainage conditions and moisture sensitivity in the material itself and underlying layers. Hence, testing individual materials will not give a full overview of the behaviour of a pavement structure in changing moisture conditions. The influence of moisture on pavement structures has been investigated successfully using heavy vehicle simulator (HVS) in research by e.g. Erlingsson (2010), Saevarsdottir \& Erlingsson (2013) and Camacho-Garita et al. (2020).

Falling weight deflectometer (FWD) is a non-destructive test commonly used for pavement response evaluation. Surface deflections resulting from a dynamic load is registered by the deflectometer, and layer moduli is backcalculated using a mechanistic model (Chen et al., 1999; Marecos et al., 2017; Cafiso et al., 2020).

In the Nordic countries, large-size (upper sieve size $\mathrm{D} \geq 90 \mathrm{~mm}$ ) unbound pavement materials are commonly used in pavement structures (Fladvad et al., 2017). Materials where D > $90 \mathrm{~mm}$ are not covered by the European standards for construction aggregates (EN 13242, 2007; EN 13285, 2018). The impact of increased moisture in large-size unbound pavement materials is not well understood, as the particle size makes laboratory methods for measuring moisture content unsuitable. Open-graded materials can be used to ensure drainage of pavement structures. Such materials may be difficult to analyse with traditional pavement design methods, because of their lack of an optimum moisture content. Degree of saturation has been found to be a valuable descriptor of the moisture conditions in pavement materials (ARA Inc., 2004; Tatsuoka \& Correia, 2018), but cannot be applied for draining materials.

To better account for expected climate changes in pavement design, experimental evaluation of large-size pavement materials' response to changing moisture content is necessary. The aim of the present research was to investigate:

1. How moisture content in pavement materials change as groundwater levels vary

2. How unbound large-size pavement materials respond to moisture changes in terms of stiffness measured by FWD.

This paper focusses on FWD measurements conducted during an accelerated pavement test (APT). Response modelling and permanent deformation modelling based on stress and strain registrations from the same APT are reported by Fladvad \& Erlingsson (2021a; 2021b).

\section{MATERIALS AND METHODS}

\subsection{Pavement structures}

Two thin flexible pavement structures were tested in an APT using an HVS. The structures were constructed in a concrete test pit which was $5 \mathrm{~m}$ wide, $15 \mathrm{~m}$ long, and $3 \mathrm{~m}$ deep. The pavement structures had a total thickness of just below $0.6 \mathrm{~m}$, and the remaining $2.4 \mathrm{~m}$ test pit depth was filled with a silty sand subgrade. Layer thicknesses for both structures are shown in Figure 1.

Both pavement structures were constructed from asphalt concrete (AC) surface and binder layers over a $0 / 32 \mathrm{~mm}$ unbound base layer. The subbase materials differed between the structures, where one structure had a wide-graded $0 / 90 \mathrm{~mm}$ crushed rock subbase with a controlled fines content, whereas the other structure had an open-graded 22/90 mm crushed rock subbase. Particle size distribution (PSD) curves for the unbound pavement materials are shown in Figure 2. 


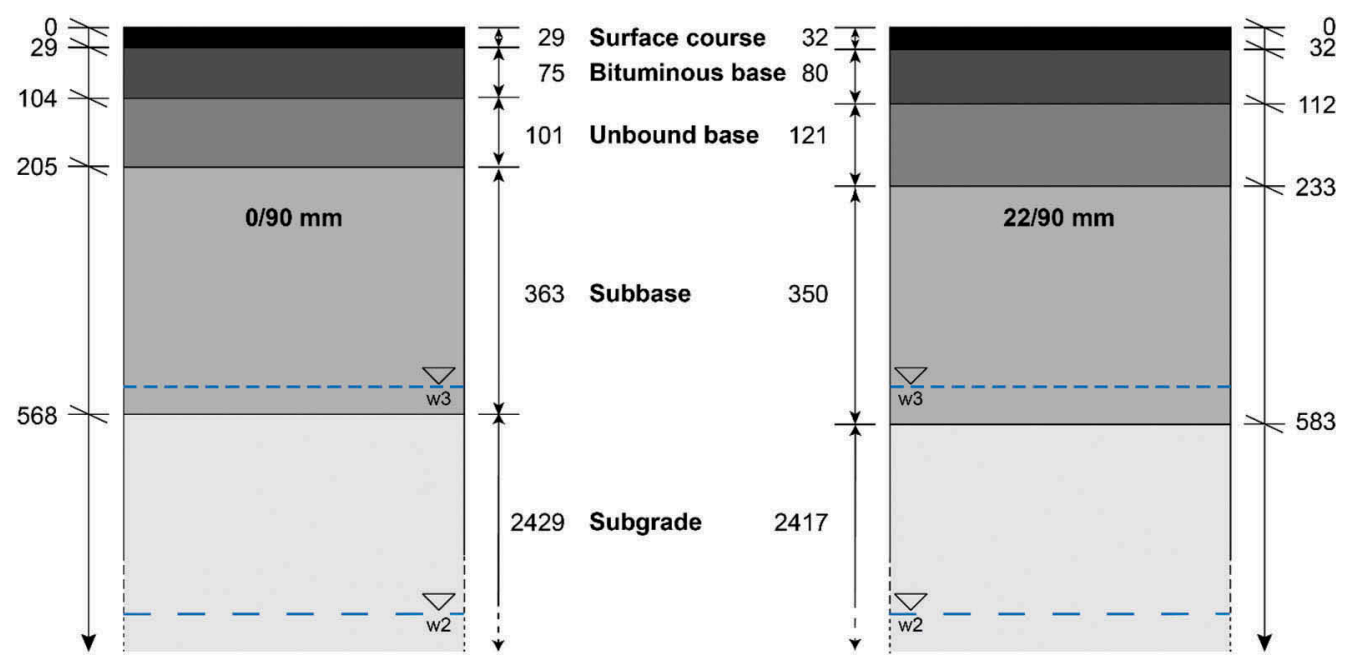

Figure 1. Outline of pavement structures. Depth below surface and layer thicknesses in mm. Blue dashed lines represent groundwater levels for phases w2 and w3.

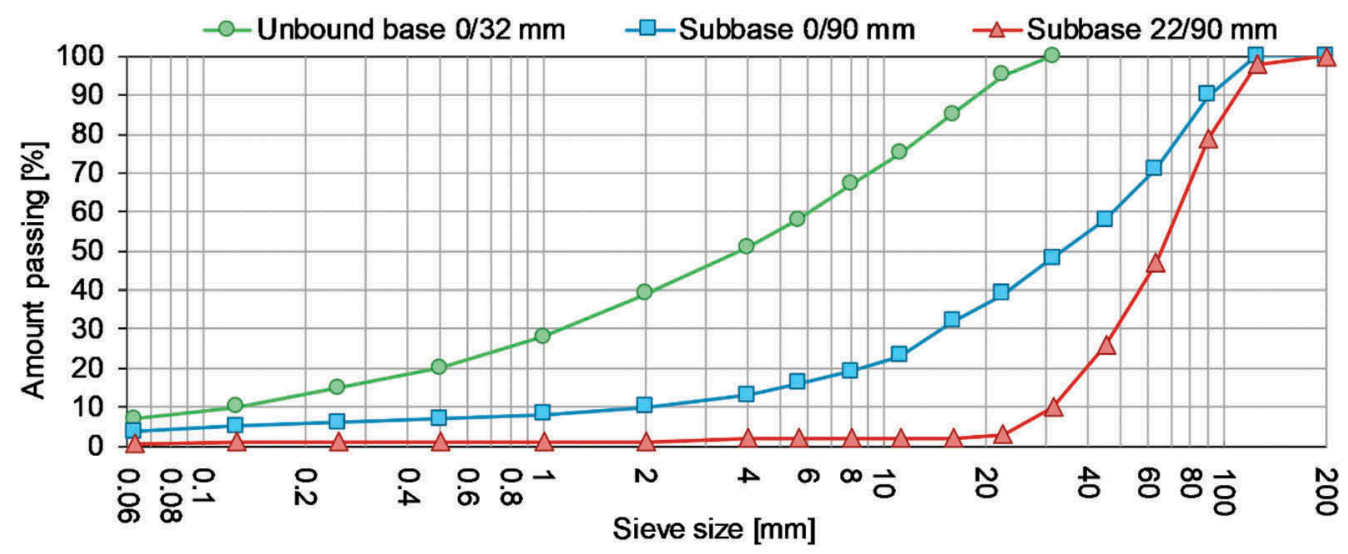

Figure 2. Particle size distribution curves for unbound base and subbase materials.

\subsection{Groundwater variations}

The pavement structures were subjected to three different groundwater levels in succession. First, the groundwater table (GWT) was located at great depth below the surface, leaving the pavement materials and subgrade in a natural moist state (phase w1). Next, in phase w2, water was added to the test pit, resulting in a constant GWT $30 \mathrm{~cm}$ below the subbase layers. This GWT level corresponds to a functioning drainage system located $30 \mathrm{~cm}$ below the pavement structure. In phase w3, GWT was additionally raised to about $5 \mathrm{~cm}$ into the subbase layers. This GWT level corresponds to an overloaded drainage system. The GWT levels from phase w2 and w3 are illustrated in Figure 1.

During phases w1-w3, the pavement structures were subjected to accelerated traffic loads. After the traffic loading finished in phase w3, GWT was lowered in steps to the levels from phases w2 and w1. 


\subsection{Falling weight deflectometer measurements}

FWD measurements were conducted in each groundwater phase. The measurements were conducted at the following times:

w1.1: Before accelerated traffic loading started

w2.1: After traffic loading in phase w2 was finished

w3.1: Before traffic loading in phase w3 started

w3.2: After traffic loading in phase w3 was finished

w2.2: When GWT was reduced to the level from phase w2

w3.2: When GWT was reduced to the level from phase w1

The measurements were conducted at ambient temperature, varying from 3.8 to $15.5^{\circ} \mathrm{C}$. Knowing the asphalt concrete stiffness $E_{T_{\text {ref }}}$ at a reference temperature $T_{r e f}$, the stiffness $E_{T}$ at a temperature $T$ can be calculated from Eq. (1). The reference stiffness $E_{T_{\text {ref }}}$ used in the calculations was $6500 \mathrm{MPa}$ at $T_{r e f} 10^{\circ} \mathrm{C}$, and $b$ was assumed 0.065 .

$$
E_{T}=E_{T_{r e f}} e^{-b\left(T-T_{r e f}\right)}
$$

\subsection{Accelerated traffic}

The pavement structures were subjected to accelerated traffic load from an HVS. The traffic was applied as bidirectional dual-wheel loading with $60 \mathrm{kN}$ dual-wheel load, corresponding to a $120 \mathrm{kN}$ axle load. The tyre pressure was $800 \mathrm{kPa}$, and the HVS kept a constant speed of $12 \mathrm{~km} / \mathrm{h}$. During traffic loading, the temperature in the heavy vehicle simulator was kept constant at $10^{\circ} \mathrm{C}$ using a climate chamber.

The accelerated traffic amounted to 1233000 load repetitions, divided between 550000 load repetitions in phase w1, 385000 load repetitions in phase w2 and 298000 load repetitions in phase w3. The total accelerated traffic load corresponds to 2.55 million 10-tonne standard axles, which again may correspond to 20 years of an annual average daily traffic (AADT) of 3000 vehicles, assuming $10 \%$ heavy vehicles.

\section{RESULTS AND DISCUSSION}

\subsection{Moisture content}

The volumetric water content in the unbound base, subbase and subgrade registered at the time of FWD measurements is summarised in Table 1 . The $\mathrm{Sb}$ registrations represent the average from two moisture sensors, while the $\mathrm{UB}$ and $\mathrm{Sg}$ moisture was registered by one sensor in each layer. The subgrade moisture is common to both structures, as both were built on the same silty sand subgrade.

The moisture registrations show that the two subbase materials, as expected, have very different moisture contents. The open-graded $22 / 90 \mathrm{~mm}$ subbase has a very low and nearly constant water content around $2 \%$, varying by only $0.5 \%$ through all groundwater phases. The well-graded $0 / 90 \mathrm{~mm}$ subbase maintains a moisture content around 7.4-8.4\%.

The moisture content in the unbound base reaches a maximum of $10.0 \%$ in both structures, but this level was reached much earlier in the $0 / 90 \mathrm{~mm}$ structure.

For the subgrade, water content varies from $12.8 \%$ in the naturally moist state (w1), to 26$28 \%$ in the fully saturated state when GWT is located above the moisture sensor.

\subsection{Falling weight deflectometer}

Table 2 shows the stiffnesses backcalculated from measured deflection at all groundwater levels. In the backcalculation, the AC stiffness is adjusted to a surface temperature of $10^{\circ} \mathrm{C}$. 
Table 1. Volumetric water content [\%] registered at the time of FWD measurements. UB - Unbound base, $\mathrm{Sb}$ - Subbase, $\mathrm{Sg}$ - Subgrade.

\begin{tabular}{lllllllll}
\hline & \multicolumn{3}{l}{$0 / 90 \mathrm{~mm}$ structure } & & \multicolumn{3}{l}{$22 / 90 \mathrm{~mm}$ structure } \\
\cline { 2 - 3 } Measurement ID & $\mathrm{UB}$ & $\mathrm{Sb}$ & $\mathrm{Sg}$ & & UB & $\mathrm{Sb}$ & $\mathrm{Sg}$ \\
\hline w1.1 & 7.7 & 7.4 & 12.8 & & 7.1 & 1.8 & 12.8 \\
w2.1 & 8.6 & 7.8 & 26.6 & & 7.2 & 1.9 & 26.6 \\
w3.1 & 8.7 & 7.9 & 26.6 & & 7.1 & 2.0 & 26.6 \\
w3.2 & 10.0 & 8.4 & 27.7 & & 10.0 & 2.3 & 27.7 \\
w2.2 & 9.3 & 7.9 & 27.5 & & 9.7 & 2.0 & 27.5 \\
w1.2 & 9.0 & 7.6 & 16.5 & & 9.6 & 1.9 & 16.5 \\
\hline
\end{tabular}

The backcalculation was conducted using the ERAPave software (Erlingsson and Ahmed, 2013). The subgrade is divided into two layers, where the boundary between the layers is the GWT level in phase w2. The subbase is divided into three layers, where the lowest layer is below the GWT in phase w3.

The backcalculated deflection results are compared in Figure 3. The results are based on 50 $\mathrm{kN}$ falling weight load.

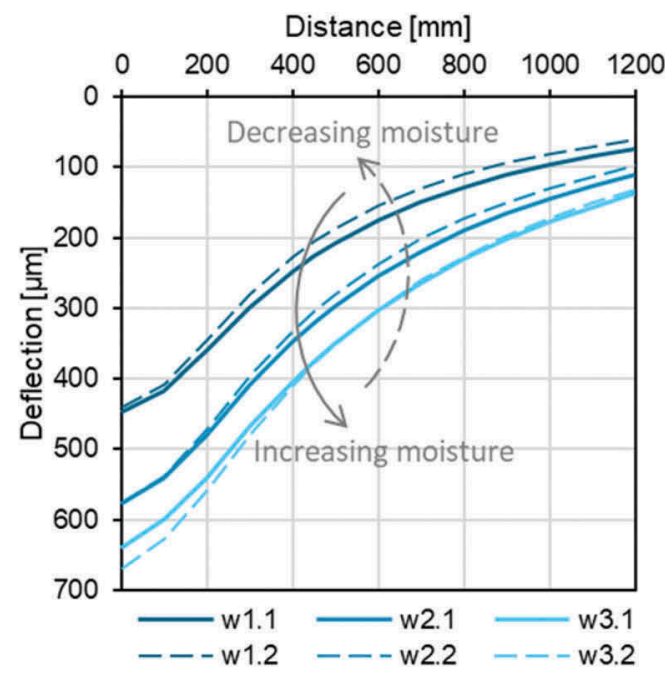

a) $0 / 90 \mathrm{~mm}$ structure

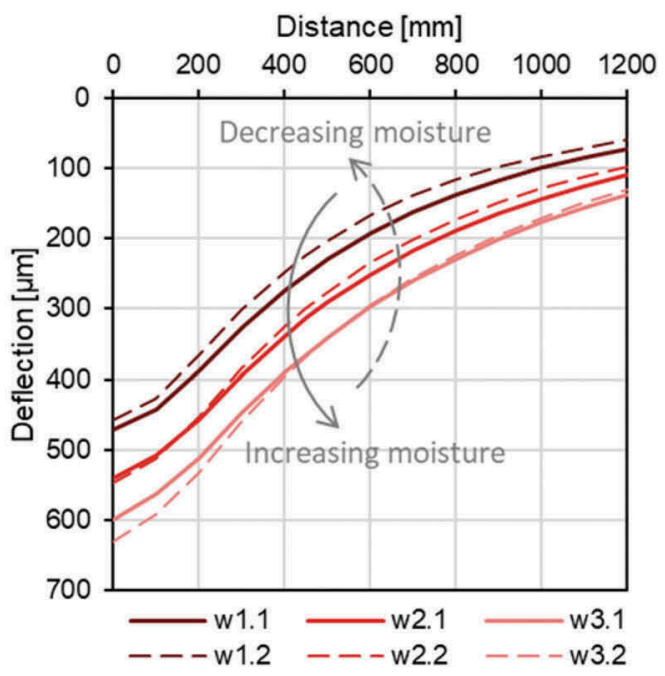

b) $22 / 90 \mathrm{~mm}$ structure

Figure 3. Backcalculated deflection, temperature adjusted to $10^{\circ} \mathrm{C}$. FWD load $50 \mathrm{kN}$.

As expected, increased GWT and moisture content resulted in increased deflection and reduced stiffness of the pavement materials. This tendency is reversed when GWT is lowered. Although the $0 / 90 \mathrm{~mm}$ structure originally shows lower deflection and higher subbase stiffness, this structure is more affected by the moisture changes and shows higher deflection than the $22 / 90 \mathrm{~mm}$ structure in phase $\mathrm{w} 2$ and $\mathrm{w} 3$. The increase in deflection in the load centre is summarised in Table 3. The difference is most 
Table 2. Backcalculated stiffnesses for pavement materials.

a) $0 / 90 \mathrm{~mm}$ structure

\begin{tabular}{llllllll}
\hline & \multicolumn{9}{l}{ Stiffness [MPa] } \\
\cline { 3 - 8 } Layers & Thickness [mm] & w1.1 & w2.1 & w3.1 & w3.2 & w2.2 & w1.2 \\
\hline Surface and binder course & 104 & 6500 & 6500 & 6500 & 5671 & 5671 & 5671 \\
Unbound base & 101 & 250 & 225 & 225 & 203 & 214 & 225 \\
Subbase 1 & 163 & 220 & 157 & 157 & 149 & 157 & 220 \\
Subbase 2 & 150 & 220 & 143 & 143 & 129 & 143 & 220 \\
Subbase 3 & 50 & 220 & 129 & 129 & 116 & 129 & 220 \\
Subgrade 1 & 300 & 82 & 66 & 44 & 46 & 70 & 98 \\
Subgrade 2 & 2132 & 82 & 53 & 44 & 46 & 60 & 98 \\
\hline
\end{tabular}

b) $22 / 90 \mathrm{~mm}$ structure

\begin{tabular}{|c|c|c|c|c|c|c|c|}
\hline \multirow[b]{2}{*}{ Layers } & \multirow[b]{2}{*}{ Thickness [mm] } & \multicolumn{6}{|c|}{ Stiffness [MPa] } \\
\hline & & w1.1 & w2.1 & w3.1 & w3.2 & w2.2 & w1.2 \\
\hline Surface and binder course & 112 & 6500 & 6500 & 6500 & 5671 & 5671 & 5671 \\
\hline Unbound base & 121 & 250 & 250 & 250 & 203 & 214 & 225 \\
\hline Subbase 1 & 150 & 143 & 143 & 143 & 135 & 143 & 154 \\
\hline Subbase 2 & 150 & 143 & 143 & 143 & 135 & 143 & 154 \\
\hline Subbase 3 & 50 & 143 & 143 & 143 & 135 & 143 & 154 \\
\hline Subgrade 1 & 300 & 82 & 66 & 44 & 46 & 70 & 98 \\
\hline Subgrade 2 & 2117 & 82 & 53 & 44 & 46 & 60 & 98 \\
\hline
\end{tabular}

prominent from phase w1 to $\mathrm{w} 2$, where the increase is about double for the $0 / 90 \mathrm{~mm}$ structure compared to the $22 / 90 \mathrm{~mm}$ structure.

Table 3. Increase of deflection in load centre, compared to phase w1.

\begin{tabular}{lll}
\hline & $0 / 90 \mathrm{~mm}$ structure & $22 / 90 \mathrm{~mm}$ structure \\
\hline w2 & $29 \%$ & $15 \%$ \\
w3 & $49 \%$ & $34 \%$ \\
\hline
\end{tabular}

The 0/90 $\mathrm{mm}$ subbase material regains its original stiffness from measurement w1.1 when the GWT is lowered to the original state in w1.2. The $22 / 90 \mathrm{~mm}$ subbase material, on the other hand, shows increased stiffness in w1.2 compared to w1.1, indicating stiffening and stabilisation due to traffic helped by moisture.

Neither subbase material showed any change in stiffness between w2.1 and w.3.1. This is likely an effect of too short time between the GWT raise and the FWD measurement, as the moisture content had not yet increased in these layers. At the time of measurement w3.2, moisture content was increased in the $0 / 90 \mathrm{~mm}$ subbase, and stiffness was decreased accordingly.

The differences in stiffness for the unbound base between the two structures in w2.1 and w3.1 can be explained by the difference in moisture content. The stiffness of the unbound base decreases more quickly in the $0 / 90 \mathrm{~mm}$ structure, corresponding to the quicker moisture increase seen in Table 1. This development is likely due to the limited 
ability of the open-graded subbase to transport moisture from the GWT to the unbound base. After long time, in measurement w3.2, the moisture content in the unbound base is the same for both structures.

The backcalculation analysis revealed a reduction of the AC stiffnesses between measurement w3.1 and w3.2. The AC stiffness reduction is likely an effect of the accelerated traffic, not the GWT variations.

For all three GW phases, the subgrade stiffness is higher in the second measurement. The increased stiffness shows that the APT has resulted in post-compaction of the subgrade.

The differences in deflection and stiffness from w3.2 to w2.2 and w1.2 are undisturbed by traffic, as these measurements were conducted after the traffic loading was finished. The results clearly show how the lowered GWT reduces deflection and increases the stiffness in all unbound layers, including the subgrade.

Tensile strain at the bottom of the AC layers caused by the FWD load was calculated from the backcalculated stiffnesses using ERAPave (Table 4). In the beginning of the test (w1.1), the tensile strain was similar in both structures, as they have the same stiffness in AC and unbound base. The maximum tensile strain was calculated in measurement w3.2, where the moisture content was highest.

Table 4. Calculated tensile strain $\varepsilon_{t}$ from FWD load at the bottom of AC layers.

\begin{tabular}{|c|c|c|}
\hline \multirow[b]{2}{*}{ Measurement ID } & \multicolumn{2}{|c|}{ Tensile strain [ustrain] } \\
\hline & 0/90 mm structure & 22/90 mm structure \\
\hline w1.1 & 224 & 224 \\
\hline w2.1 & 248 & 226 \\
\hline w3.1 & 251 & 229 \\
\hline w3.2 & 280 & 262 \\
\hline w2.2 & 270 & 253 \\
\hline w1.2 & 246 & 246 \\
\hline
\end{tabular}

The allowable number of load repetitions $N_{f}$ to cause fatigue cracking is related to the tensile strain $\varepsilon_{t}$ at the bottom of AC layers through Eq. (2) (Huang, 2012).

$$
N_{f}=f_{1}\left(\varepsilon_{t}\right)^{-f_{2}}
$$

To quantify the consequences of the increased $\varepsilon_{t}$ caused by increased moisture content in the pavement, $N_{f}$ for phase w1 and w3 can be compared. Assuming $f_{2}=4, \varepsilon_{t}$ from w3.2 reduces $N_{f}$ to $41 \%$ compared to w1.1 for the $0 / 90 \mathrm{~mm}$ structure, and $53 \%$ for the $22 / 90 \mathrm{~mm}$ structure.

For the $0 / 90 \mathrm{~mm}$ structure, when surface deflection increases by $49 \%$, the tensile strain under the AC increases by $25 \%$, and the fatigue life time is reduced to only $41 \%$ of the original. Similarly for the $22 / 90 \mathrm{~mm}$ structure; surface deflection increases by $34 \%$, tensile strain increases by $17 \%$ and the fatigue life time is reduced to $53 \%$ of the original. All these indicators show that the $0 / 90 \mathrm{~mm}$ structure is more affected by the raised GWT than the $22 / 90 \mathrm{~mm}$ structure.

\subsection{Particle Size Distribution (PSD)}

Figure 4 displays PSD curves for the subbase materials before and after accelerated pavement testing. Post testing samples were collected separately from the upper and lower parts of the subbase layers. Each sample weighed minimum $80 \mathrm{~kg}$. 
For the $0 / 90 \mathrm{~mm}$ subbase, amount of material increased in the size from 1-20 mm, and decreased from $40-125 \mathrm{~mm}$. For the $22 / 90 \mathrm{~mm}$ subbase, amount of material increased from $20-45 \mathrm{~mm}$, and decreased from $63-125 \mathrm{~mm}$. Both materials showed an increase in fines < $0.063 \mathrm{~mm}$.

Both subbase materials show degradation in the form of abrasion and fragmentation as a result of the construction process and traffic loading. However, the FWD results show that the structural capacity of the pavement layers has not been reduced; the $22 / 90 \mathrm{~mm}$ even show increased stiffness in measurement w1.2 compared to w1.1.

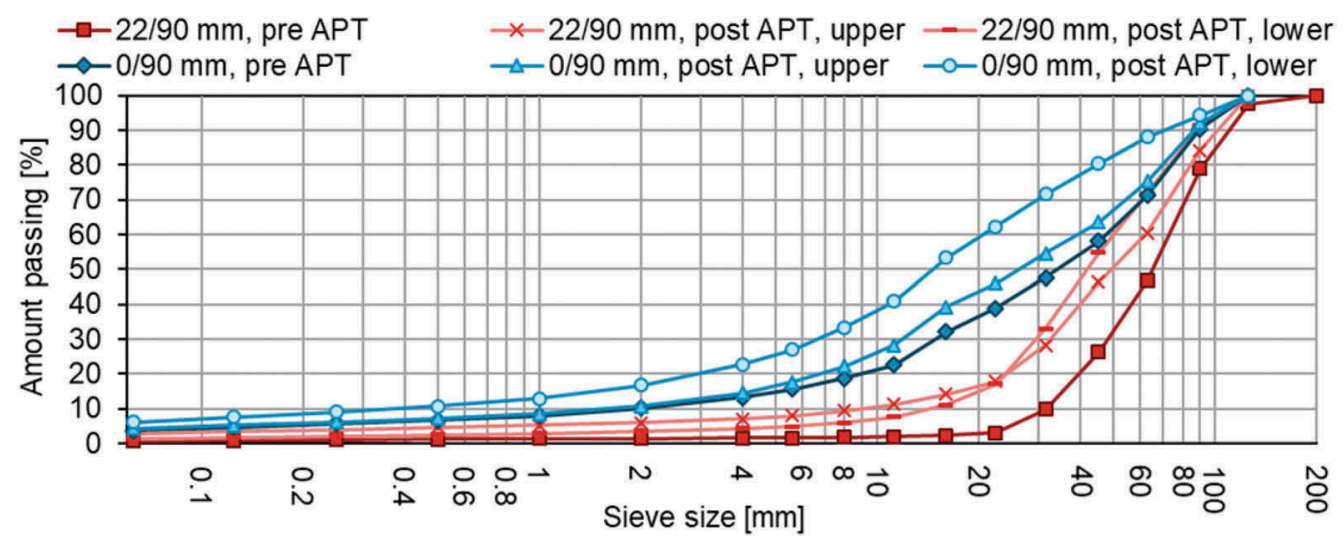

Figure 4. Particle size distribution curves before and after accelerated pavement testing.

\section{CONCLUSIONS}

Two flexible pavement structures were evaluated using FWD as GWT beneath the structures moved and induced changes in the moisture content of the pavement materials. Differences in the response of unbound pavement materials to changing moisture conditions were successfully measured by FWD.

The bearing capacity of the pavement structures were affected by the changing GWT beneath and in the pavement structure. For the well-graded structure, the moisture content increased in the unbound base even when GWT was raised only to $30 \mathrm{~cm}$ below the subbase, showing how the moisture development in pavement materials are affected by material choice in adjoining layers.

Using an open-graded subbase material makes the structure less affected by changes in the GWT:

- Increasing GWT from great depth to the design drainage level increased deflection by $15 \%$ for the open-graded structure, and $29 \%$ for the well-graded structure.

- GWT corresponding to an overloaded drainage system led to a $34 \%$ increase in deflection for the open-graded structure, and a $49 \%$ increase in the well-graded structure.

- Although the open-graded structure had lower stiffness at the beginning of the test, this structure was less affected by the groundwater changes and showed a $7.7 \%$ increase in subbase stiffness after the APT.

- The fatigue life time is substantially reduced in both structures as GWT is raised, but the 0/ $90 \mathrm{~mm}$ structure is most heavily affected.

Both structures show less deflection after 1.23 million load repetitions than in the measurement conducted before the accelerated traffic started, although the moisture content is higher in all layers in the final measurement. This shows that both structures were able to withstand 
substantial traffic load without degradation of their bearing capacity even though the PSD curves show some degradation of the aggregate particles in the subbase layers.

Pavement and drainage design must account for increased precipitation and more intense rainfall events in order to limit damage caused by increased moisture in pavement materials.

\section{ACKNOWLEDGEMENTS}

The research presented in this paper was financed by the Norwegian Public Roads Administration. The testing was conducted at the Swedish National Road and Transport Research Institute. The authors would like to thank the construction company Veidekke for supplying the subbase materials for the APT.

\section{REFERENCES}

ARA Inc. (2004) Guide for the Mechanistic-Empirical Design of New and Rehabilitated Pavement Structures, Final report, NCHRP 1-37A. Washington DC, USA. Available at: http://onlinepubs.trb.org/ onlinepubs/archive/mepdg/guide.htm.

Cafiso, S., Di Graziano, A., Fedele, R., Marchetta, V., \& Praticò, F. (2020). 'Sensor-based pavement diagnostic using acoustic signature for moduli estimation'. International Journal of Pavement Research and Technology, 13(6), 573-580. doi: 10.1007/s42947-020-6007-4

Camacho-Garita, E. et al. (2020) 'Effect of Moisture on Full-Scale Pavement Distress', Journal of Testing and Evaluation, 48(1), p. 20180902. doi: 10.1520/JTE20180902.

Chen, J., Hossain, M. and Latorella, T.M. (1999). 'Use of Falling Weight Deflectometer and Dynamic Cone Penetrometer in Pavement Evaluation', Transportation Research Record, 1655(1):145-151. doi:10.3141/1655-19

Elshaer, M., Ghayoomi, M. and Daniel, J. S. (2019) 'Impact of subsurface water on structural performance of inundated flexible pavements', International Journal of Pavement Engineering, 20(8), pp. 947957. doi: $10.1080 / 10298436.2017 .1366767$.

EN 13242 (2007) Aggregates for unbound and hydraulically bound materials for use in civil engineering work and road construction EN 13242:2002+A1:2007. Brussels, Belgium: European Committee for Standardization.

EN 13285 (2018) Unbound mixtures - Specifications EN 13285:2018. Brussels, Belgium: European Committee for Standardization.

Erlingsson, S. (2010) 'Impact of Water on the Response and Performance of a Pavement Structure in an Accelerated Test', Road Materials and Pavement Design, 11(4), pp. 863-880. doi: 10.1080/ 14680629.2010.9690310.

Erlingsson, S. and Ahmed, A. W. (2013) 'Fast layered elastic response program for the analysis of flexible pavement structures', Road Materials and Pavement Design, 14(1), pp. 196-210. doi: 10.1080/ 14680629.2012 .757558$.

Fladvad, M., Aurstad, J. and Wigum, B. J. (2017) 'Comparison of practice for aggregate use in road construction - results from an international survey', in Loizos, A., Al-Qadi, I., and Scarpas, T. (eds) Bearing Capacity of Roads, Railways and Airfields. Athens, Greece: CRC Press, pp. 563-570. doi: 10.1201/ 9781315100333-74.

Fladvad, M. and Erlingsson, S. (2021a) 'Modelling the response of large-size subbase materials tested under varying moisture conditions in a heavy vehicle simulator', Road Materials and Pavement Design. doi: 10.1080/14680629.2021.1883462.

Fladvad, M. and Erlingsson, S. (2021b) 'Permanent deformation modelling of large-size unbound pavement materials tested in a heavy vehicle simulator under different moisture conditions', Road Materials and Pavement Design. doi: 10.1080/14680629.2021.1883464.

Huang, Y. H. (2012) Pavement Analysis and Design. 2nd edn. Pearson Education Inc.

Lekarp, F. and Dawson, A. R. (1998) 'Modelling permanent deformation behaviour of unbound granular materials', Construction and Building Materials, 12(1), pp. 9-18. doi: 10.1016/S0950-0618(97) 00078-0.

Lu, D., Tighe, S. L. and Xie, W.-C. (2018) 'Impact of flood hazards on pavement performance', International Journal of Pavement Engineering, pp. 1-7. doi: 10.1080/10298436.2018.1508844.

Marecos, V., Fontul, S., de Lurdes Antunes, M., \& Solla, M. (2017). 'Evaluation of a highway pavement using non-destructive tests: Falling Weight Deflectometer and Ground Penetrating Radar'. Construction and Building Materials, 154, 1164-1172. doi: 10.1016/j.conbuildmat.2017.07.034 
Saevarsdottir, T. and Erlingsson, S. (2013) 'Water impact on the behaviour of flexible pavement structures in an accelerated test', Road Materials and Pavement Design. Taylor \& Francis, 14(2), pp. 256277. doi: $10.1080 / 14680629.2013 .779308$.

Seneviratne, S. et al. (2012) 'Changes in climate extremes and their impacts on the natural physical environment', in Field, C. B. et al. (eds) Managing the Risk of Extreme Events and Disasters to Advance Climate Change Adaptation. A Special Report of Working Groups I and II of the Intergovernmental Panel on ClimateChange (IPCC). Cambridge, UK, and New York, NY, USA: Cambridge University Press, pp. 109-230. Available at: https://www.ipcc.ch/site/assets/uploads/2018/03/SREX-Chap3_F INAL-1.pdf.

Tatsuoka, F., \& Correia, A. G. (2018). 'Importance of controlling the degree of saturation in soil compaction linked to soil structure design'. Transportation Geotechnics, 17, 3-23. doi: 10.1016/j. trgeo.2018.06.004 